\title{
Correction to: Impacts of channel wall twisting on the mixing enhancement of a novel spiral micromixer
}

\section{Dariush Bahrami $^{1} \cdot$ Morteza Bayareh $^{1}$}

Published online: 21 October 2021

C Institute of Chemistry, Slovak Academy of Sciences 2021

\section{Correction to: Chemical Papers}

https://doi.org/10.1007/s11696-021-01876-5

In this article the wrong figure appeared as Figs. 5a and 10C.

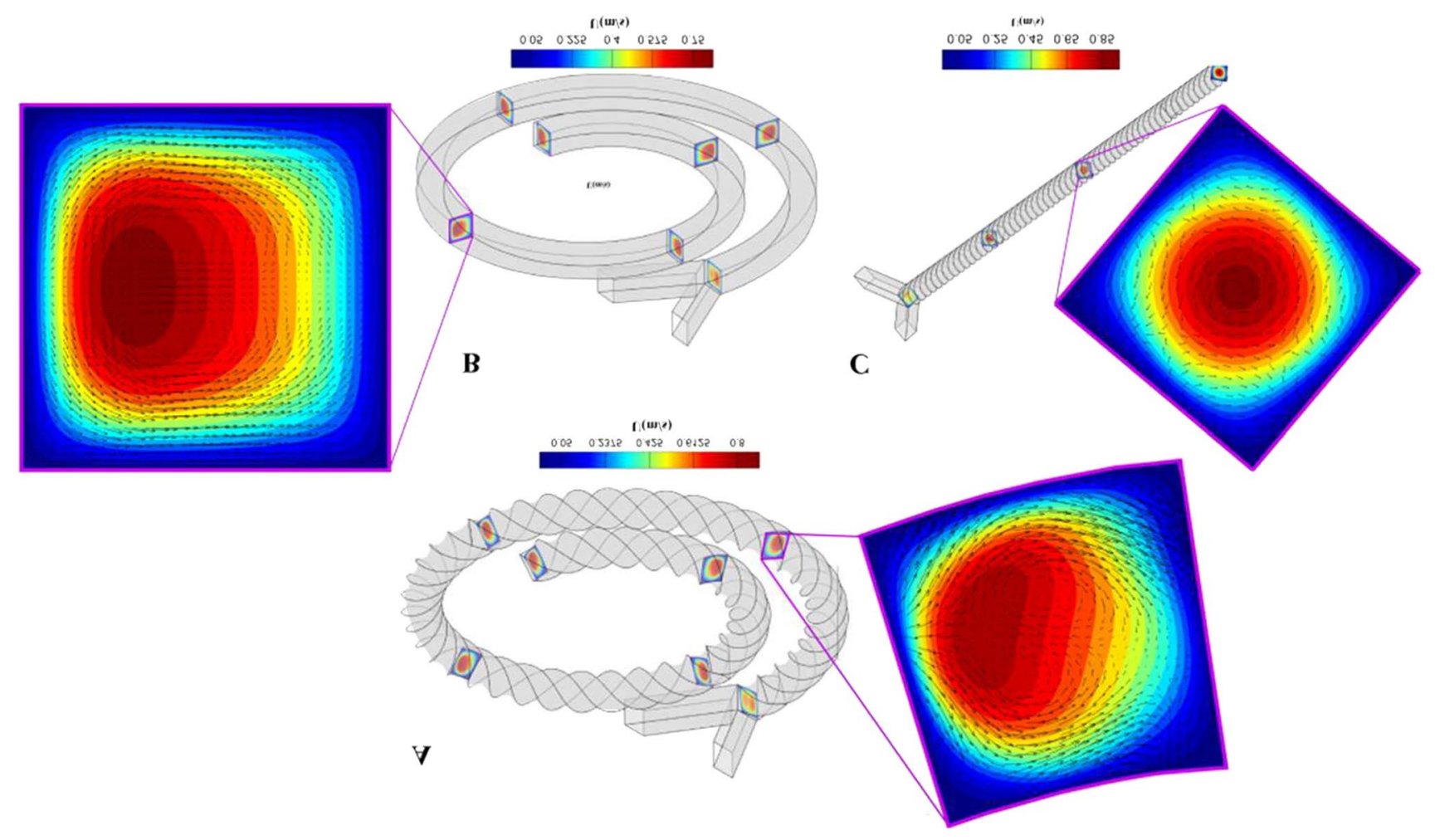

The original article can be found online at https://doi.org/10.1007/ s11696-021-01876-5.

Morteza Bayareh

m.bayareh@sku.ac.ir

1 Department of Mechanical Engineering, Shahrekord University, Shahrekord, Iran 


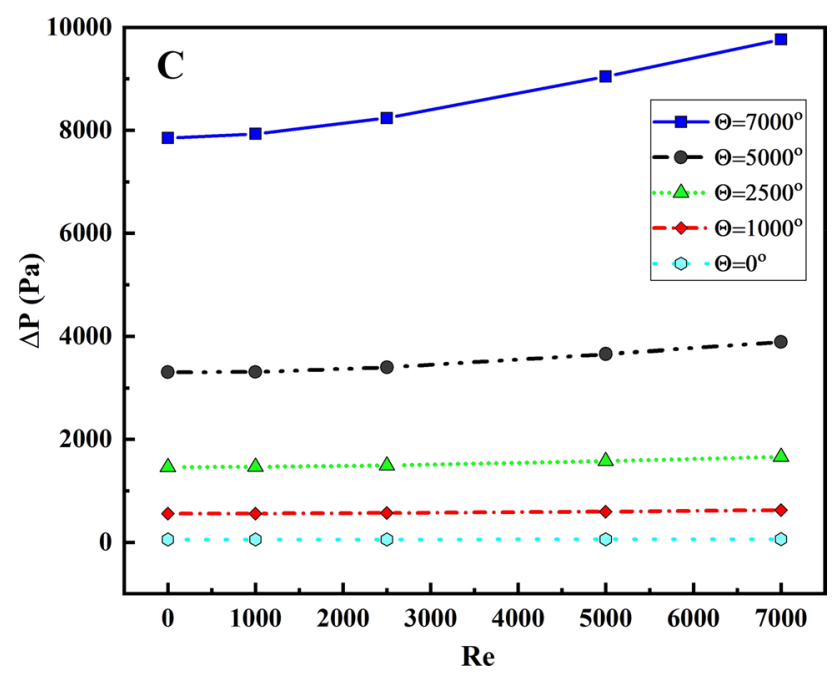

The figure should have appeared as shown below.

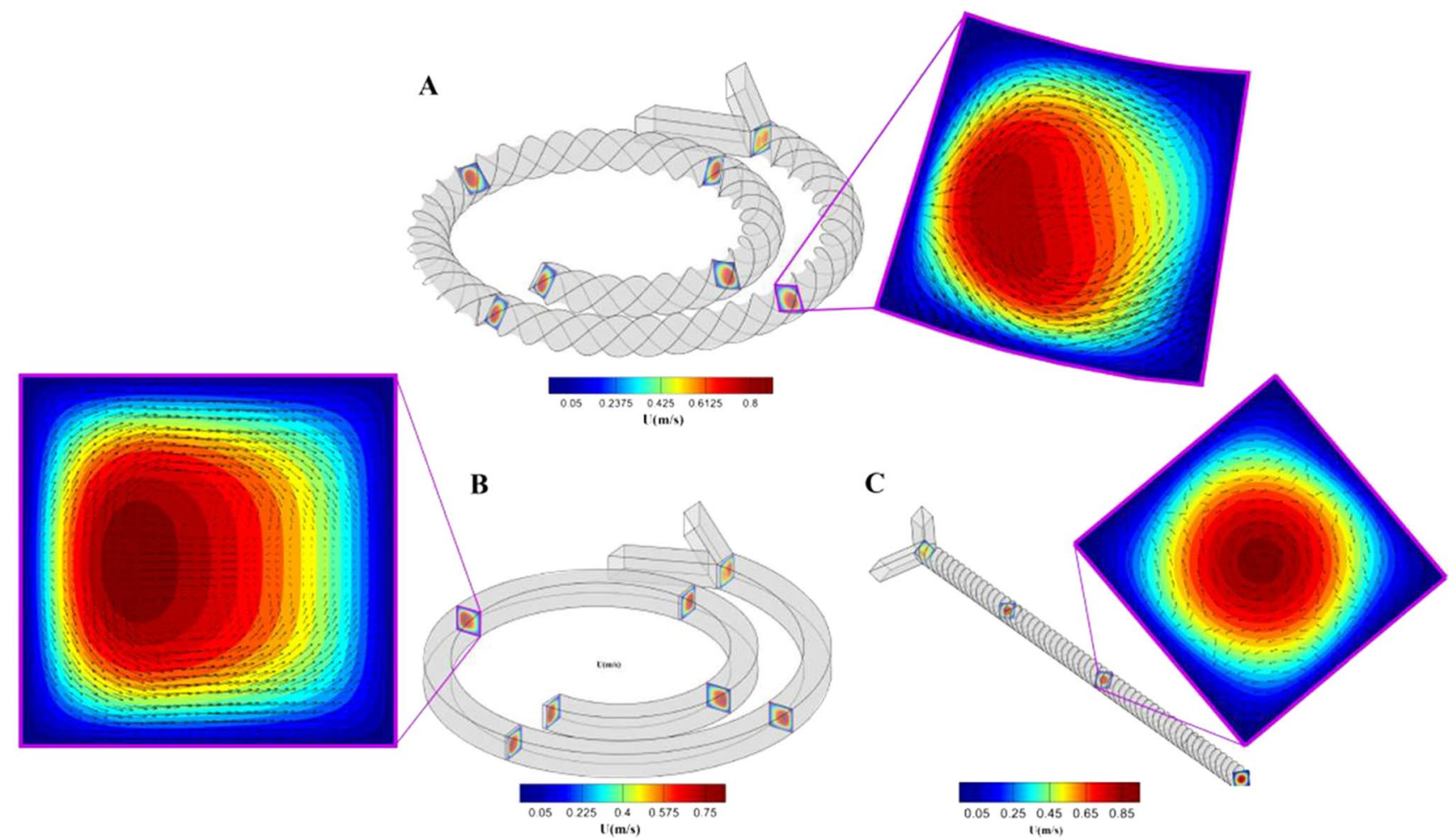


The original article has been corrected.

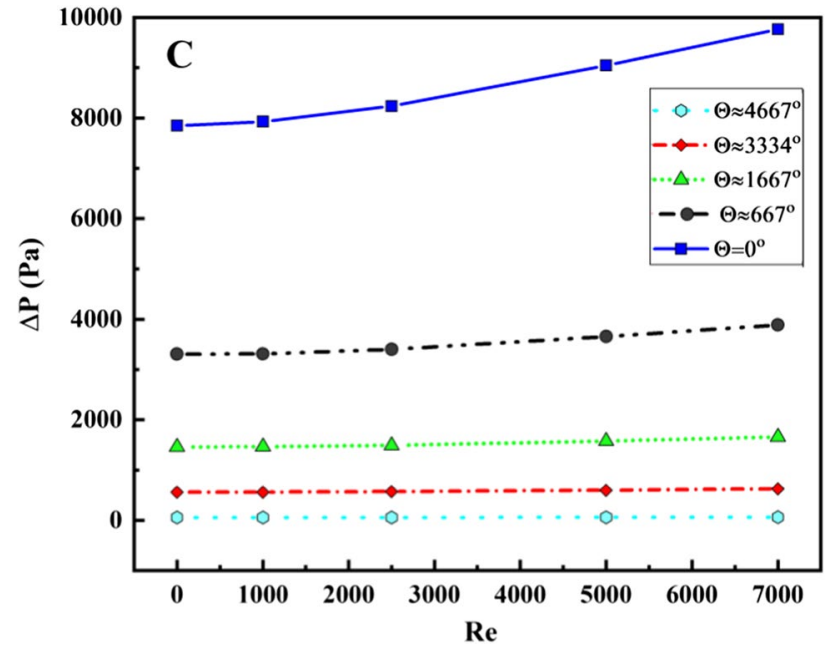

Publisher's Note Springer Nature remains neutral with regard to jurisdictional claims in published maps and institutional affiliations. 